Int. J. Dev. Biol. 58: 863-871 (2014)

doi: $10.1387 / \mathrm{ijdb} .140316 \mathrm{kk}$

\title{
Reptile genomes open the frontier for comparative analysis of amniote development and regeneration
}

\author{
MARC TOLLIS, ELIZABETH D. HUTCHINS and KENRO KUSUMI* \\ School of Life Sciences, Arizona State University, Tempe, AZ, USA
}

\begin{abstract}
Developmental genetic studies of vertebrates have focused primarily on zebrafish, frog and mouse models, which have clear application to medicine and well-developed genomic resources. In contrast, reptiles represent the most diverse amniote group, but have only recently begun to gather the attention of genome sequencing efforts. Extant reptilian groups last shared a common ancestor $\sim 280$ million years ago and include lepidosaurs, turtles and crocodilians. This phylogenetic diversity is reflected in great morphological and behavioral diversity capturing the attention of biologists interested in mechanisms regulating developmental processes such as somitogenesis and spinal patterning, regeneration, the evolution of "snake-like" morphology, the formation of the unique turtle shell, and the convergent evolution of the four-chambered heart shared by mammals and archosaurs. The complete genome of the first non-avian reptile, the green anole lizard, was published in $\mathbf{2 0 1 1}$ and has provided insights into the origin and evolution of amniotes. Since then, the genomes of multiple snakes, turtles, and crocodilians have also been completed. Here we will review the current diversity of available reptile genomes, with an emphasis on their evolutionary relationships, and will highlight how these genomes have and will continue to facilitate research in developmental and regenerative biology.
\end{abstract}

KEY WORDS: reptile, genomics, gene expression, somitogenesis, regeneration

\section{Introduction}

A major goal of developmental genomics is to understand the genetic mechanisms underlying vertebrate patterning and differentiation. The most successful and diverse group of modern land-adapted vertebrates are amniotes, and they display a wide array of forms, from parakeets to people to pythons. This diversity comes with the opportunity to learn about shared and divergent pathways regulating development during the evolution of the vertebrate body plan. Much has been learned, through comparisons of amniote (chicken and mouse) and anamniote (zebrafish and Xenopus) developmental and genomic models, about molecular mechanisms that underlie important pathways. The human genome project brought with it the initial promise that we would one day understand the true origins of human genes and genetic disorders (Lander et al., 2001) and the more recent advent of next-generation sequencing technologies has yielded assembled genome representatives for most mammalian orders (Chinwalla et al., 2002; Lindblad-Toh et al., 2005; Liu et al., 2009; Mikkelsen et al., 2007; Wade et al., 2009; Warren et al., 2008; Zhang et al.,
2013) in addition to 28 avian genomes (Table 1; Zhang et al., 2014). These sequences are freely available to the scientific community as the foundation for developmental studies. For instance, one could easily navigate to the University of California, Santa Cruz (UCSC) Genome Browser (available at http://genome.ucsc.edu/) and access the complete genomes of 48 mammals and five of the aforementioned birds. Next-generation sequencing has facilitated genomic studies of non-traditional model organisms at a cheaper cost, and the genomes of many more vertebrate species are being sequenced, contributing to the Genome $10 \mathrm{~K}$ project (Genome $10 \mathrm{~K}$ Community of Scientists, 2009). Of the more than 30,000 living amniote species, almost 10,000 are reptiles, yet there have been relatively few genomic resources available for non-avian reptiles until only very recently. This is despite the fact that non-avian reptiles contain far more diversity than mammals and birds in many aspects of development and physiology. Here we will review the phylogenetic diversity of currently available reptile genomes, and discuss how they have contributed to the knowledge of vertebrate developmental biology. Also, we will review current and potential avenues of research that are shedding light on comparative studies

*Address correspondence to: Kenro Kusumi. School of Life Sciences, PO Box 874501, Tempe, AZ 85287, USA. Tel: +1-480-727-8993. Fax: +1-480-965-6899.

Web: http://kusumi.lab.asu.edu - E-mail: Kenro.Kusumi@asu.edu

Accepted: 19 December 2014

ISSN: Online 1696-3547, Print 0214-6282

(c) 2014 UBC Press

Printed in Spain 
Fig. 1.Vertebrate phylogeny highlighting reptiles with complete genome sequences. Select model organisms are included as outgroups (Danio rerio, Xenopus tropicalis, Mus musculus). Names of key vertebrate clades are given at the appropriate nodes in the phylogeny (Tetrapoda, Amniota, Sauropsida, Archosauria). The only remaining extant lineage of the Synapsida is the mammals. The evolutionary relationships of the modern reptilian lineages (Lepidosauria, Testudines and Crocodilia) and the species for which there are complete genomes available las of November 2014) are featured. Birds (represented here by Gallus gallus) are in the Archosauria, see Table 1 for avian genome resources. ${ }^{*}$ There is not currently a complete genome available for Sphenodon, but it is included in the phylogeny to bring attention to the phylogenetic position of tuataras.

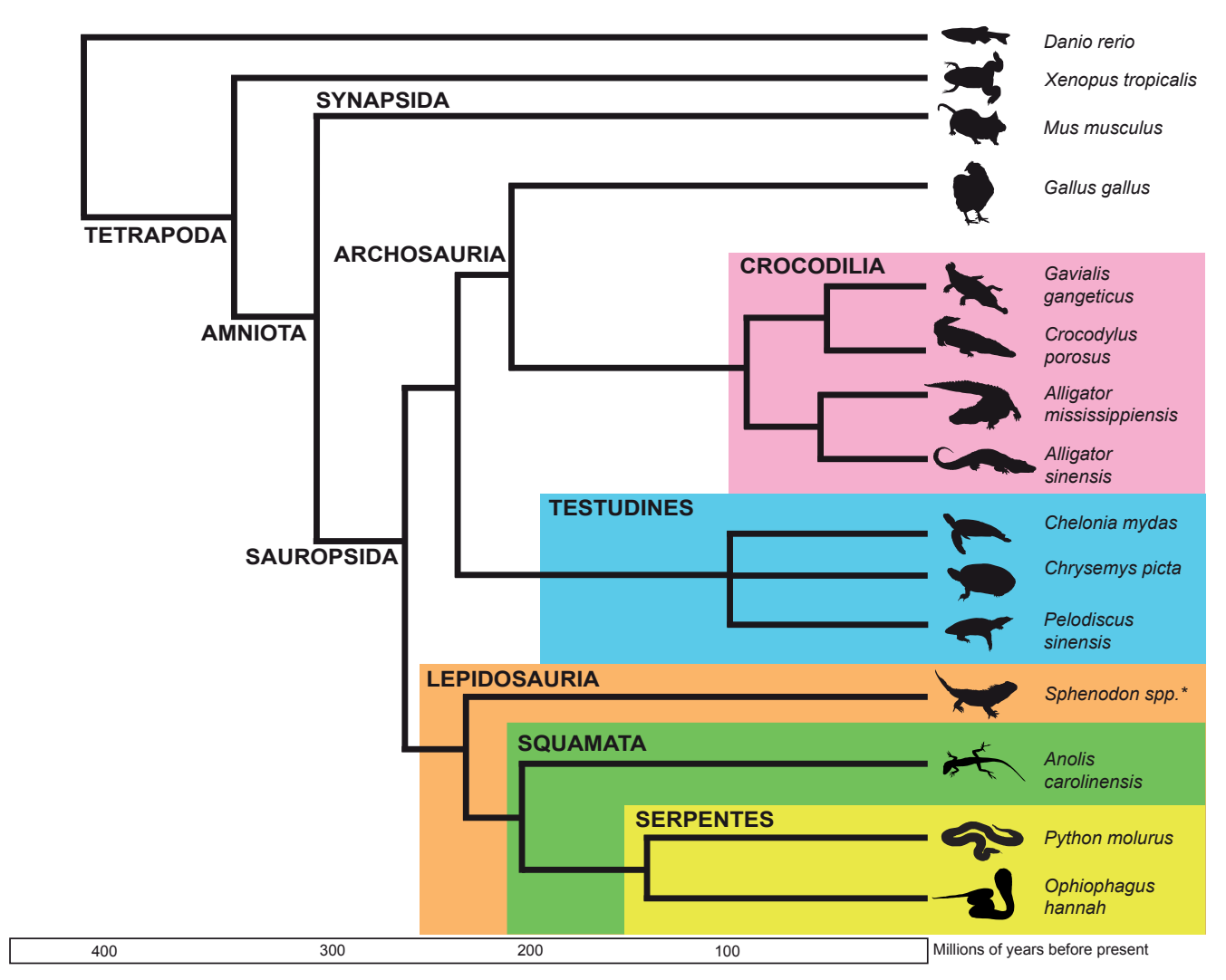

of regenerative capacity. Here, we will use the term "reptiles" in the historical sense to include the following: Testudines, or all living turtles; Crocodilia, or alligators, caimans, gharials and crocodiles; and Lepiodosauria, or all lizards, snakes, amphisbaenians (or all squamates) and the tuatara. For each of these groups, we will review their unique sets of adaptations and phenotypes, and how genome-sequencing efforts have facilitated work in that area.

The traditional class "Reptilia" refers to the living ectothermic amniotes. Although they share with amphibians several aspects of lifestyle, behavior, ecology and a whole field of study known as herpetology, as amniotes reptiles are more closely related to mammals and birds. After radiating into terrestrial environments during the Carboniferous around 320-310 million years ago (Donoghue, Benton, 2007; Pyron, 2010) (Fig. 1), amniotes split into two recognized groups based on cranial morphology: synapsids and sauropsids (Benton, 2005). The synapsids include all mammals as well as many extinct lineages of "mammal-like reptiles" from the Permian and Mesozoic Eras (i.e., pelycosaurs, therapsids and cynodonts). Synapsids reached the peak of their diversity in the Permian, and most lineages disappeared at the Permian-Triassic boundary extinction event; the remaining extant synapsids constitute class "Mammalia". While their ancestors were similar in many respects to modern reptiles, modern mammals differ a great deal from reptiles in several important traits such as endothermy, mammary glands, fur, and the eutherian placenta.

The second amniote group is the sauropsids, which includes all living reptiles and birds, and originated 250-280 million years ago (Fig. 1). Sauropsids survived the Permian-Triassic extinction and diversified to dominate terrestrial and marine environments throughout the Mesozoic Era. The evolutionary history of sauropsids includes a Lepidosauria branch and a branch containing the order Testudines and the Archosauria, which includes birds and crocodiles. While the surviving modern reptiles constitute "saurian" reptiles, birds evolved from dinosaurs (Gauthier 1986; Brusatte et al., 2010) and so are also sauropsids, albeit with a set of highly derived set of "non-reptilian" constraints such as endothermy, feathers, and flight. A recent integration of developmental and paleontological evidence has clarified patterns of loss, fusion and re-evolution of wrist features that were integral to the early evolution of flight in bird-like dinosaurs and their avian descendants (Botelho et al., 2014). When focusing on the "reptilian" sauropisds, the times to the most recent common ancestors of Testudines, Archosauria, and Lepidosauria are on average much older ( $\sim 240$ million years) than those between the modern placental mammalian orders ( $\sim 100$ million years) and even between placental mammals and monotremes $(\sim 200$ million years ago) (Donoghue, Benton, 2007; Pyron, 2010), making the sequence of divergence between the sauropsid orders - and thus the ancestral states of various developmental milestones and divergent phenotypes - a controversial subject. One major area of disagreement has been the placement of turtles on phylogenetic trees. Turtles have a unique body plan, the most obvious trait being the shell, as well as a lack of temporal fenestrae in the turtle skull, differing greatly from the skulls of synapsids and other sauropsids that do contain fenestrae. Earlier studies based on anatomy and paleontology placed turtles in the sister lineage to all other amniotes ("Parareptilia") (Benton, 2005). Some more recent genetic work has suggested that turtles form a clade with lepidosaurs (Lyson et al., 2012). However, the majority of genomic evidence supports a turtle-archosaur clade (Crawford et al., 2012; Crawford et al., 2014; Shaffer et al., 2013; Wang et al., 2013) and it is likely that the loss of temporal fenestrae was 
a signature trait in the early evolution of turtles (Kuratani et al., 2011) and we adopt this approach in this review (Fig. 1).

\section{Genomic resources for Reptiles}

\section{Complete genomes for Lepidosauria}

The first reptile to have a complete genome sequence was a lepidosaur, the green anole lizard (Anolis carolinensis), which was made available by the Broad Institute in 2007 and published in 2011 (Table 1; Alföldi et al., 2011). It was mainly chosen to bridge the phylogenetic gap between chicken and human for comparative genomic studies in order to understand the origin of human genes (Janes et al., 2010), and its initial analysis yielded important insights to the evolution of amniote genomes (Alföldi et al., 2011). For instance, very few chromosomal rearrangements have occurred since $A$. carolinensis diverged from chicken $\sim 280$ million years ago, and there is a high degree of synteny conservation. In addition, the lack of isochores in the green anole genome suggested for the first time that GC content may be less integral to genomic integrity that previously thought (Fujita et al., 2011).

Since the release of the green anole genome, the genomes of two other lepidosaurs have been made available. The first was the Burmese python (Python molurus bivittatus), which was announced in 2011 (Castoe et al., 2011) and its complete genome was published in 2013 (Castoe et al., 2013). The analysis of the python genome highlighted large variation in gene expression associated with changes in organ size and metabolism due to the feast-and-famine lifestyle of snakes. Two other lepidosaur genomes belong to snakes as well: the king cobra (Ophiophagus hannah) was sequenced to better understand the regulatory components and evolutionary origins of the complex venom system (Vonk et al., 2013), while the first analysis of the speckled rattlesnake (Crotalus mitchelli) draft genome focused on multiple episodes of endogenous viral element integration (Gilbert et al., 2014).

\section{Complete genomes for Testudines}

The first published turtle genome was that of the western painted turtle (Chrysemys picta), and its initial analysis focused on the molecular bases of tooth loss, immunity, longevity and adaptations for anoxic conditions (Shaffer et al., 2013). Following the release of the painted turtle genome was an analysis of two other turtle genomes, the green sea turtle (Chelonia mydas) and the Chinese softshell turtle (Pelodiscus sinensis), which used gene expression analyses to understand common and divergent developmental patterns across amniotes with a focus on the unique turtle shell (Wang et al., 2013). Combined, these resources provide a firm foundation for future studies on development in turtles, which significantly diverges from the ancestral amniote morphology.

\section{Complete genomes for Crocodilia}

While they traditionally have been placed in the class "Reptilia", crocodilians are archosaurian reptiles that share common ancestry within modern birds (Brusatte et al., 2010), and therefore have the most promise for understanding genomic and developmental

TABLE 1

SAUROPSIDS, INCLUDING REPTILES AND BIRDS, WITH AVAILABLE COMPLETE GENOME SEQUENCES

\begin{tabular}{|c|c|c|c|c|c|}
\hline Scientific name & Common name & Order & Family & Year reported & DOI \\
\hline \multicolumn{6}{|l|}{ LEPIDOSAURIA } \\
\hline Anolis carolinensis & Green anole & Squamata & Dactyloidae & Data released 2007 & $10.1038 /$ nature 10390 \\
\hline Python molurus & Burmese python & Squamata & Pythonidae & 2011 & $10.1186 / \mathrm{gb}-2011-12-7-406$ \\
\hline Ophiophagus hannah & King cobra & Squamata & Elapidae & 2013 & $10.1073 /$ pnas. 1314702110 \\
\hline \multicolumn{6}{|l|}{ TESTUDINES } \\
\hline Chrysemys picta bellii & Western painted turtle & Testudines & Emydidae & 2013 & 10.1186/gb-2013-14-3-r28 \\
\hline Pelodiscus sinensis & Chinese soft-shelled turtle & Testudines & Trionychidae & 2013 & 10.1038/ng.2615 \\
\hline Chelonia mydas & Green sea turtle & Testudines & Chelonidae & 2013 & $10.1038 /$ ng.2615 \\
\hline \multicolumn{6}{|l|}{ CROCODILIA } \\
\hline Gavialis gangeticus & Indian gharial & Crocodilia & Gavialidae & 2012 & 10.1186/gb-2012-13-1-415 \\
\hline Crocodylus porosus & Saltwater crocodile & Crocodilia & Crocodylidae & 2012 & 10.1186/gb-2012-13-1-415 \\
\hline Alligator mississippiensis & American alligator & Crocodilia & Alligatoridae & 2012 & $10.1186 / \mathrm{gb}-2012-13-1-415$ \\
\hline Alligator sinensis & Chinese alligator & Crocodilia & Alligatoridae & 2013 & 10.1038/cr.2013.104 \\
\hline \multicolumn{6}{|l|}{ AVES } \\
\hline Anas platyrhynchos & Mallard duck & Anseriformes & Anatidae & 2013 & $10.1038 /$ ng.2657 \\
\hline Falco cherrug & Saker falcon & Falconiformes & Falconidae & 2013 & 10.1038/ng.2588 \\
\hline Falco peregrinus & Peregrine falcon & Falconiformes & Falconidae & 2013 & $10.1038 / n g .2588$ \\
\hline Gallus gallus & Chicken & Galliformes & Phaisanidae & 2004 & $10.1038 /$ nature 03154 \\
\hline Meleagris gallopavo & Turkey & Galliformes & Phaisanidae & 2010 & 10.1371/journal.pbio. 1000475 \\
\hline Tetrao tetrix & Black grouse & Galliformes & Phaisanidae & 2014 & $10.1186 / 1471-2164-15-180$ \\
\hline Pseudopodoces humilis & Tibetian ground tit & Passeriformes & Paridae & 2013 & 10.1186/gb-2013-14-3-r29 \\
\hline Taeniopygia guttata & Zebra finch & Passeriformes & Estrildidae & 2010 & $10.1038 /$ nature 08819 \\
\hline Geospiza fortis & Medium ground-finch & Passeriformes & Thraupidae & Data released 2012 & $10.5524 / 100040$ \\
\hline Geospiza magnirostris & Large ground-finch & Passeriformes & Thraupidae & 2013 & $10.1186 / 1471-2164-14-95$ \\
\hline Ficedula albicollis & Collared flycatcher & Passeriformes & Muscicapidae & 2012 & 10.1038/nature11584 \\
\hline Ficedula hypoleuca & Pied flycatcher & Passeriformes & Muscicapidae & 2012 & $10.1038 /$ nature 11584 \\
\hline Amazona vittata & Puerto Rican parrot & Psittaciformes & Psittacidae & 2012 & $10.1186 / 2047-217 X-1-14$ \\
\hline Melopsittacus undulatus & Budgerigar & Psittaciformes & Psittaculidae & 2011 & $10.1186 / 2047-217 X-3-11$ \\
\hline
\end{tabular}


evolution in the avian lineage (Fig. 1). The International Crocodilian Genomes Working Group (www.crocgenomes.org) published preliminary assemblies for the American alligator (Alligator mississippiensis), the saltwater crocodile (Crocodylus porosus) and the Indian gharial (Gavialis gangeticus), and provide transcriptome data from various tissues to aid in annotation, as well as bacterial artificial chromosome (BAC) sequences to improve assemblies (St John et al., 2012). Final assemblies and annotations for these species, as well as a robust evolutionary analysis shedding light on the ancestral evolution of the archosaur lineage was subsequently produced by the same group (Green et al., 2014). The genome of a fourth crocodilian species, the Chinese alligator (Alligator sinensis), which is listed as critically endangered on the International Union for Conservation of Nature (IUCN) Red List (http://www. iucnredlist.org/details/867/0) was sequenced and analyzed in the context of molecular adaptations to long-period diving behavior. Lineage-specific expansions of genes related to the robust crocodilian immune system were found in the Chinese alligator genome (Wan et al., 2013).

\section{Transcriptomic resources for Reptiles}

While the complete sequencing of a reference genome will certainly facilitate studies of genes and their expression and can shed light on developmental processes, the de novo sequencing and assembly of transcriptomes by way of next-generation sequencing technologies (i.e., RNA-Seq) in the absence of a reference genome has also been useful (Gibbons et al., 2009). To date, several transcriptome resources have been developed for reptiles lacking a complete genome, including the western terrestrial garter snake (Thamnophis elegans) (Schwartz et al., 2010) and the common chameleon (Chamaeleo chamaeleon) (Bar-Yaacov et al., 2013). Complete brain transcriptomes have been generated for the Nile crocodile (Crocodylus niloticus), the corn snake (Pantherophis gutattus), the bearded dragon (Pogona vitticeps) and the red-eared slider turtle (Trachemys scripta) (Tzika et al., 2011) (available at www.reptilian-transcriptomes.org), and the vomeronasal organ transcriptome has been generated for the corn snake (Brykczynska et al., 2013).

A particularly valuable resource will be the transcriptome of the tuatara (Sphenodon punctatus) (Miller et al., 2012), which is a non-squamate lepidosaur (Fig. 1). Sphenodon is the surviving genus of the order Rhyncocephalia, which had a global distribution until the late Cretaceous (65-80 million years ago) (Apesteguía, Novas, 2003). The range of Sphenodon today is limited to a few small islands in New Zealand. Until there is a complete genome, the tuatara transcriptome will facilitate future research in various avenues of genomic evolution and conservation of reptiles. As complete genomes are now available for all major groups of reptiles (lepidosaurs, turtles and archosaurs), these transcriptomes can be easily mapped to their nearest relatives (Sphenodon to Anolis, for example), and can help shed light on the diversity and numbers of reptilian transcripts and how they differ from current model amniotes representing mammals and birds.

\section{Evolution of gene families in reptiles}

Based on prediction and homology alone, the green anolegenome was initially reported to contain 17,472 protein-coding genes that were largely predicted through ab initio efforts (Alföldi et al., 2011).
A subsequent transcriptome-based annotation increased the gene number to 22,962 (Eckalbar et al., 2013), which is comparable to other amniotes. In comparison, 25,385 genes were annotated in the python genome (Castoe et al., 2013), although only $68 \%$ of these contained a protein domain. 21,796 protein-coding genes were found in the painted turtle genome (Shaffer et al., 2013), and $\sim 22,200$ were reported in the Chinese alligator (Wan et al., 2013). The initial prediction for the chicken genome was that it contained between 20,000 and 23,000 protein coding genes (International Chicken Genome Sequencing Consortium, 2004). The mouse genome (GRCm38, accessed from www.ensmbl.org) contains 22,592 protein coding genes, and the number of protein coding genes found in the human genome by the ENCODE project was 20,687 (The ENCODE Project Consortium, 2012), although recent work shows that this number for humans could be reduced to less than 20,000 (Ezkurdia et al., 2014). This suggests that the total number of expected genes in any amniote genome should be in the range of 20,000 genes. Nonetheless, gene evolution across amniotes has been dynamic with considerable gene family loss and/or expansion since the time of divergence between the living vertebrates. For instance, the green anole lizard genome contained 3,994 protein coding genes with one-to-one orthologues in human, mouse, dog, opossum, platypus, chicken, zebra finch and pufferfish (Alföldi et al., 2011), which is considerably less than the total number of predicted genes for each of these genomes and suggests a high degree of gene duplication and loss during the evolution of these lineages.

The differences in various gene family expansions between reptiles and mammals are substantial, and have been linked to particular adaptations that are unique to each lineage. For instance, 11 opsin gene families were present in the green anole lizard genome as well as several species of invertebrate, fish and frog, but are absent in mammals (Alföldi et al., 2011) and this was related to the superior color vision in lizards when compared to most mammals. In addition, the green anole lizard genome featured significant duplications and expansion of several egg protein gene families, with an elevated rate of molecular evolution that indicates episodic positive selection and bouts of adaptation. Vivipary, or the birth of live young, evolved early and often during the diversification of squamates (115 times versus 140 in all vertebrates) (Pyron, Burbrink, 2014), with frequent reversions to ovipary which would require many changes in egglaying at the molecular level during sauropsid evolution. Indeed, out of the 276 protein-encoding genes expressed in the eggs of $A$. carolinensis, only 50 orthologues were confirmed in chicken, suggesting high turnover. Significant expansion of olfactory receptor families were found in the soft shell turtle genome, including 1,137 intact and possibly functional genes which is an amount similar to what is found in most mammals (Wang et al., 2013). Other examples of reptile-specific and functionally-related gene family expansion are the venom proteins in snakes, as revealed by comparisons between the python and king cobra genomes (Castoe et al., 2011; Vonk et al., 2013), and the contrasting evolutionary patterns of vomeronasal receptor repertoires that were observed between mammals and reptiles (Brykczynska et al., 2013).

\section{Genome vs. transcriptome based expression studies in reptiles}

Though genomes are continually being released, there are many species of interest for which a genome is not available. Mapping 
RNA-Seq reads to the reference genome of the same species remains the "gold standard" for gene expression studies (Fig. 2A) (Guttman et al., 2010; Trapnell et al., 2012); however, for those species without an available genome, one option for analysis is de novo transcriptome assembly (Fig. $2 \mathrm{~B}$ ). There are many tools available for de novo transcriptome assembly and differential expression analysis of these transcriptomes (Davidson, Oshlack, 2014; Grabherr et al., 2011; Haas et al., 2013; Robertson et al., 2010; Schulz et al., 2012) In cases where the reference genome is of low quality, i.e., with misassemblies and large genomic deletions, genes of interest that are absent in the genome assembly can be present in the transcriptome (Park et al., 2014). Another possible approach is mapping assembled transcriptomes to a closely related reference genome, which has been utilized with non-human primates, across the mammalian clade, and the zebra finch and human genomes (Fig. 2C) (Benjamin et al., 2014; Hornett, Wheat, 2012; Vijay et al., 2012). In silico mapping to distant reference genomes with up to $15 \%$ sequence divergence outperformed mapping to de novo transcriptome assemblies, generally recovering more of the transcriptome and reducing the number of mismappings from poorly annotated genes (Vijay et al., 2012). Another study found that mapping to divergent species within 100 million years apart represented more genes than mapping to the transcriptome alone, with similar results to those derived from high quality genomes (Hornett, Wheat, 2012).

\section{Examples of developmental studies using reptilian genome resources}

\section{Evolution of genetic pathways regulating somitogenesis in reptiles}

There are a number of morphologically divergent features observed in reptiles that are not seen in mammals, particularly in the vertebral column. First, there is an underlying genetic diversity in the regulatory networks that shape vertebral segments that has been revealed through comparative studies adding reptiles in the analysis (Eckalbar et al., 2012; Gomez et al., 2008). Second, there is greater diversity of vertebral segment number and allocation along the body axis (reviewed in Keyte \& Smith, 2014; Kusumi et al., 2013; Richardson et al., 1998). Unlike mammals, which are generally constrained to having only seven cervical vertebrae, reptiles display a great diversity of vertebral segment number expansions.

Among tetrapods, there are differences in vertebral morphology and development between the amniotes and amphibians. Since many amphibians have both aquatic and terrestrial life stages, there is development of both a larval spine as seen in tadpoles and subsequent axial reorganization in metamorphosis to adult morphology (Handrigan, Wassersug, 2007; Trueb, Hanken, 1992). In contrast, amniote tetrapods completely form their vertebrae during embryogenesis (reviewed in Rawls, Fisher, 2010). Since the mouse, chick and Xenopus frog are developmental model systems, their vertebral development has been well characterized (Burke et al., 1995; Christ et al., 2000; Gossler, Tam, 2002; Ročková, Roček, 2005; Trueb, Hanken, 1992). Molecular studies of axial development have been reported in different species of squamates (Cohn, Tickle, 1999; Eckalbar et al., 2012; Gomez et al., 2008). The evolution of spinal diversity derives from changes in developmental mechanisms controlling the size of vertebral elements, segment number and distribution (lumbar, sacral, caudal, etc.), and embryonic timing (reviewed in Gomez, Pourquie, 2009).

The formation of axial segments, or somites, is regulated by genetic networks regulated by the Notch, Wnt, and FGF pathways collectively called the 'segmentation clock' (reviewed in Kusumi et al., 2013). Most of what we understand about the segmentation clock has been restricted to studies in four model systems (mouse, chicken, frog, and zebrafish) with the following conserved features (EM, O, 2008; Holley, 2007; Krol et al., 2011; Sparrow, 2008): i) Posterior gradients of FGF8, WNT3a, and hairy/enhancer of split

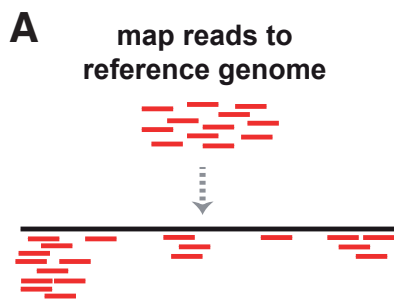

Fig. 2. Read mapping methods for differential expression analysis of RNASeq data. (A) With a complete reference genome (shown in black), it is advantageous to map RNA-Seq reads (shown in red) to the genome and then perform differential expression testing. (B) Without a complete reference genome, it is possible to first assemble a reference transcriptome de novo (shown in blue) and then map RNA-Seq reads to the transcriptome contigs. (C) A third method is to assemble a reference transcriptome de novo, map RNA-Seq reads to the reference transcriptome, and then BLAST reference transcriptome contigs to a closely related complete genome. This is followed by normalization of read abundance and counts and differential expression testing. This third approach makes it possible to combine multiple transcriptome contigs that may represent the same gene and to use robust annotations from a related species, allowing for more accurate differential expression testing than method $B$.
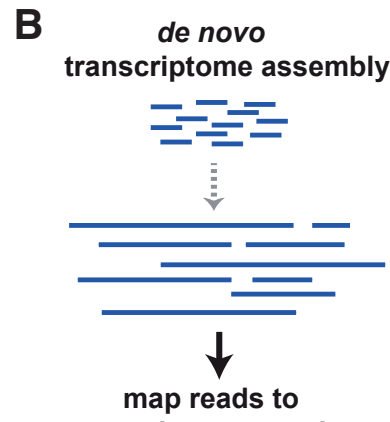

transcriptome contigs
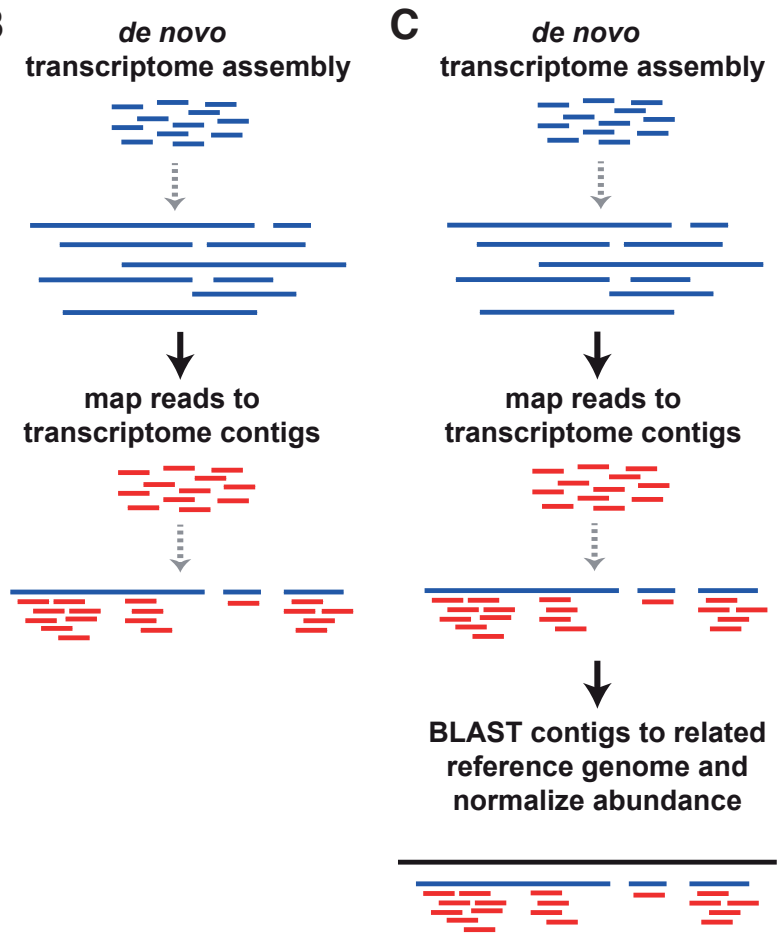
(HES and HER) proteins and rostral gradient of retinoic acid in the unsegmented paraxial mesoderm, ii) cyclical expression of genes in the Notch, Wnt, and FGF pathways, iii) the mesp2gene that integrates segmentation network gene information at the determination front. In the segmentation clock, information from gradients of gene expression within the presomitic mesoderm (PSM) is integrated with the expression of genes that are cyclically transcribed in that tissue. Somite boundaries are determined based on the periodic interaction of the cycling genes and these gradients. These four model organisms of focus for previous studies of somitogenesis do not capture the full diversity of vertebrates. Analysis of somitogenesis in the green anole lizard and the American alligator identified convergence in cycling expression (lunatic fringe in both mouse and chicken, but not in anole or alligator) and conservation of genes expressed in gradients in the presomitic mesoderm in both squamates and anamniotes (hes6 in green anole, Xenopus, and zebrafish) (Eckalbar et al., 2012).

Axial identity and boundaries of Hox gene expression are also set during somitogenesis (Alexander et al., 2009; Zákány et al., 2001). Mutations in the Notch pathway effector Rbpj were shown to disrupt the dynamic expression of Hoxd1 and Hoxd3, and, in transgenic mice with dominant negative alleles of DIl1 that have reduced Notch signaling in the PSM, there are homeotic vertebral transformations and subtle changes of Hoxgene expression (Cordes et al., 2004). In homozygous Lfng null mutants and in transgenic animals overexpressing Lfng, vertebral identities were altered, numbers of segments in the cervical and thoracic regions were reduced, and expression of Hoxb6 was shifted rostrally. Altogether, these findings confirm that the segmentation process is coupled to the determination of axial identity through Notch pathway regulation of Hox expression.

Snakes are some of the most striking examples of both increased number of vertebral segments combined with loss of limbs (Caldwell, 2003; Gans, 1975; Greer, 1987; Greer, 1991; Lande, 1978). The emergence of a "snake-like" morphology is estimated to have arisen independently at least twenty-five times in the squamates (Brandley et al., 2008; Wiens et al., 2006). Molecular studies of the corn snake identified that generation of over 300 vertebral segments was associated with both increased rate of the segmentation clock rate together with increased formation of presomitic mesoderm in the tailbud (Gomez et al., 2008). There was also an expansion in expression of thoracic Hox genes in the python (Cohn \& Tickle, 1999). With the whole genome sequencing of additional squamates, we will better understand whether common or divergent genetic regulatory changes are driving the repeated evolution of "snake-like" morphology.

\section{Regeneration in lizards}

Regeneration of appendages occurs throughout vertebrates, though the extent of regeneration varies throughout taxa (Bely, Nyberg, 2010). Amphibians and teleost fish are spectacular examples of limb and tail regeneration (Stocum, Cameron, 2011). Many lizards are capable of tail regeneration following tail amputation and/or autotomy, and tail regeneration in alligators has been reported in the field (Han et al., 2005). Birds and mammals have limited regenerative capacity in comparison, though some neonatal and juvenile mammals can regenerate digit tips, and African spiny mice can autotomize and regenerate skin (Han et al., 2008). As amniotes, lizards are the most closely related organisms to mammals that can regenerate whole structures, and the green anole has a reference genome and robust annotation (Alföldi et al., 2011; Eckalbar et al., 2013), allowing for transcriptome-wide studies of molecular pathways and mechanisms involved in lizard tail regeneration.

Though the regenerating tail has a different structure than the original tail, it is an impressive example of regeneration of cartilage, de novo muscle groups, skin, vasculature, and neural ependymal cells (Fisher et al., 2012; Gilbert et al., 2013; Hutchins et al., 2014; McClean \& Vickaryous, 2011; Ritzman et al., 2012). While blastema formation is fairly well characterized during limb and fin regeneration in amphibians and teleost fish, lizards follow a different mechanism of regeneration. Blastema formation is traditionally characterized by dedifferentiation of tissue, proliferating cells focused at the tip of the regenerating appendage, and the absence of a vascular bed (Iten \& Bryant, 1973; Mescher, 1996; Peadon \& Singer, 1966; Singer, 1974; Smith \& Wolpert, 1975). However, there is no evidence of dedifferentiation in the lizard (Cox, 1969; Fisher et al., 2012; Hughes \& New, 1959; Hutchins et al., 2014; Simpson, 1965). Additionally, in the leopard gecko (Eublepharis macularius) and green anole (A. carolinensis), proliferating cells are present throughout the regenerating tail, and the distal tip is highly vascular (Hutchins et al., 2014; McClean, Vickaryous, 2011).

Though there is a lack of evidence for blastema formation in regenerative squamates, studies of the molecular basis of tail regeneration have shown many shared pathways with other vertebrates (Hutchins et al., 2014). There are hundreds of genes that are differentially expressed along the proximal-distal axis of the regenerating tail, including those related to wound healing, musculoskeletal development, hormonal response, embryonic morphogenesis, and the Wnt and MAPK/FGF signaling pathways. The Wnt pathway in particular has been identified as a key regulator of regeneration in the salamander limb blastema (Knapp et al., 2013; Wu et al., 2013) and mouse digit tip (Takeo et al., 2013). It is possible that all vertebrates have inherited the innate genetic and regulatory repository associated with regeneration. What is unclear is why some lineages, such as mammals, have lost the ability to regenerate in the adult stage despite conserving the genes involved in regrowth. Unlike anamniote models zebrafish or salamander, lizards can provide information on amniote-specific pathways and patterns necessary for regeneration.

\section{Carapace and plastron formation and tooth loss in turtles}

The shell is a novel phenotype that unites all turtles, and comprises of a set of highly derived morphologies which combine to create a bony shield on both the dorsal (known as the carapace) and ventral sides (known as the plastron) of the animal. While fossil turtles are well known due to the fact that their hard and bony shells fossilize quite readily, the very early and rapid appearance of a complete shell in turtle evolutionary history has contributed to a relative lack of transitional forms in the fossil record. The oldest known turtle, Odonotochelys, (Li et al., 2008) was found in 220 million year old deposits in China and has a complete plastron and an under-developed carapace. This pattern matches the emergence of the turtle shell during embryonic development, which diverges significantly from the more conserved ancestral amniote condition (Gilbert, 2001) The painted turtle genome revealed significant gene family expansions in beta-keratins which play an important role in the formation of the shell, and mRNAs extracted from Pseudemys 
nelsonishell precursor cells revealed independent patterns of betakeratin involvement in turtle shells and bird feathers (Shaffer et al., 2013). Cross-species gene expression profiling between chicken and softshell turtle embryos suggest a conserved vertebrate phylotypic period, followed by significant turtle-specific repatterning of 233 genes whose gene ontology categories include ossification and extracellular matrix regulation, as well as crucial roles of 212 microRNAs and a co-option of the Wnt signaling pathway in the development of the carapacial ridge (Wang et al., 2013). Another key trait of turtles that differs from other reptiles is tooth loss, which has been associated with extensive generation of pseudogenes, including degradation of tooth-specific genes such as enamelin (ENAM), which contains multiple stop codons and non-conserved sequence (Shaffer et al., 2013). The availability of genomic resources for turtles will continue to shed light on the development of the characteristic traits of this enigmatic group.

\section{Development and evolution of the archosaurian heart}

The septation of the heart tube to form a four-chambered heart arose independently in mammals and in archosaurian reptiles. The emergence of this developmental septation process represents a well-known case of evolutionary convergence (Farmer, 1999). While it makes sense that the metabolic demands of flight would lead to cardiac septation in birds, modern crocodilians have a much more ectothermic "reptilian" lifestyle, and the four-chambered heart is likely a vestigial trait that was ancestral to highly active and likely endothermic stem archosaurs. Astudy of non-crocodilian reptiles (the turtle $T$. scripta and the green anole $A$. carolinensis) that focused on gene expression in developing ventricles showed that turtles and lizards initially form a ventricular chamber which homogeneously expresses the $T b \times 5$ transcription factor, while in chicken and mouse $T b \times 5$ expression is restricted to a left ventricle and excluded from the prospective right ventricle (Koshiba-Takeuchi et al., 2009). Transgenic ectopic expression of Tbx5 in the prospective right ventricular region of mice led to loss of the ventricular septum, and changes in genetic regulation of $T b \times 5$ are thought to have arisen independently in the avian and mammalian lineages.

\section{How will further reptile genomes advance comparative developmental studies?}

Next-generation sequencing technologies promise to increase the number of reptilian genomes - adding to the currently available four lepidosaurs, three turtles, and four crocodilians - to allow the research community to address many unresolved questions using comparative methods. While it has been shown that the mapping of transcripts to a moderately distantly related reference genome could prove useful, highly divergent genes, which can be of great interest, are underrepresented in analyses without an available reference genome. Using only transcriptomes, it is difficult to study cis- regulatory elements, copy number variation, transposable elements, and noncoding RNAs, which can be important regulators of gene expression. The continuing availability of reptile genomes will provide more resources for comparative gene expression studies. For instance, squamates are sorely unrepresented as there are currently four available complete genomes out of $>9,400$ species. Squamates as a group contain many convergent phenotypes, such as leglessness, and their genomes would be a prime resource for understanding the development of axial and appendicular morpholo- gies. Given the ever-increasing pace of ease and affordability of genome sequencing projects in the next-generation sequencing era, it is likely that the current gaps in phylogenetic sampling across reptiles will begin to get bridged, and a true appreciation for the diversity of forms across amniotes will emerge.

\section{Acknowledgements}

The research carried out by the authors and reviewed in this publication was supported by the National Institute of Arthritis and Musculoskeletal and Skin Diseases of the National Institutes of Health under Award Number R21 AR064935 and funding from Arizona State University. The content is solely the responsibility of the authors and does not necessarily represent the official views of the National Institutes of Health.

\section{References}

ALEXANDER T, NOLTE C, and KRUMLAUF R (2009). Hox genes and segmentation of the hindbrain and axial skeleton. Ann Rev Cell Dev Biol 25: 431-456.

ALFÖLDI J, DI PALMA F, GRABHERR M, WILLIAMS C, KONG L, MAUCELI E, RUSSELL P, LOWE CB, GLOR RE, JAFFE JD, RAY DA et al. (2011). The genome of the green anole lizard and a comparative analysis with birds and mammals. Nature 477: 587-591.

APESTEGUÍAS and NOVAS FE (2003). Large Cretaceous sphenodontian from Patagonia provides insight into lepidosaur evolution in Gondwana. Nature 425:609-612.

BAR-YAACOV D, BOUSKILA A, and MISHMAR D (2013). The first Chameleon transcriptome: comparative genomic analysis of the OXPHOS system reveals loss of COX8 in Iguanian lizards. Genome Biol Evol 5: 1792-1799.

BELY AE and NYBERG KG (2010). Evolution of animal regeneration: re-emergence of a field. Trends Ecol Evo. 25: 161-170.

BENJAMIN AM, NICHOLS M, and BURKE TW (2014). Comparing reference-based RNA-Seq mapping methods for non-human primate data. BMC Genomics 5.

BENTON M (2005). Vertebrate Paleontology, 3rd ed. Blackwell Science Ltd, Oxford, UK.

BOTEHLO JF, OSSA-FUENTES L, SOTO-ACUÑAS, SMITH-PAREDES D, NUÑEZLÉON D, SALINAS-SAAVEDRA M, RUIZ-FLORES M, and VARGAS AO (2014). New developmental evidence clarifies the evolution of wrist bones in the dinosaurbird transition. PLoS Biol 12(9): e1001957.

BRANDLEY MC, HUELSENBECK JP, and WIENS JJ (2008). Rates and patterns in the evolution of snake-like body form in squamate reptiles: evidence for repeated re-evolution of lost digits and long-term persistence of intermediate body forms. Evolution: 2042-2064.

BRUSATTE SL, BENTON MJ, and DESOJO JB (2010). The higher-level phylogeny of Archosauria (Tetrapoda: Diapsida). J Syst Paleontol 8: 3-47.

BRYKCZYNSKA U, TZIKA AC, RODRIGUEZ I, and MILINKOVITCH MC (2013). Contrasted evolution of the vomeronasal receptor repertoires in mammals and squamate reptiles. Genome Biol Evol 5: 389-401.

BURKE AC, NELSON CE, MORGAN BA, and TABIN C (1995). Hox genes and the evolution of vertebrate axial morphology. J Embryol Exp Morphol 121: 333-346.

CALDWELLMW (2003). "Without a leg to stand on": on the evolution and development of axial elongation and limblessness in tetrapods. Can J Earth Sci 40: 573-588.

CASTOE TA, DE KONING A, and HALL KT (2011). Sequencing the genome of the Burmese python (Python molurus bivittatus) as a model for studying extreme adaptations in snakes. Genome Biol 12: 406.

CASTOE TA, DE KONING AP, HALL KT, CARD DC, SCHIELD DR, FUJITAMK, RUGGIERO RP, DEGNER JF, DAZA JM, GU W et al. (2013). The Burmese python genome reveals the molecular basis for extreme adaptation in snakes. Proc Natl Acad Sci USA 110: 20645-20650.

MOUSE GENOME SEQUENCING CONSORTIUM, WATERSTON RH, LINDBLADTOH K, BIRNEY E, ROGERS J, ABRIL JF, AGARWAL P, AGARWALA R, AINSCOUGH R, ALEXANDERSSON M, AN P et al. (2002). Initial sequencing and comparative analysis of the mouse genome. Nature 420: 520-562.

CHRISTB, HUANG R, and WILTING J (2000). The development of the avian vertebral column. Anat Embryol 202: 179-194.

COHN MJ and TICKLE C (1999). Developmental basis of limblessness and axia patterning in snakes. Nature 399: 474-479. 
CORDES R, SCHUSTER-GOSSLER K, SERTH K, and GOSSLER A (2004). Specification of vertebral identity is coupled to Notch signaling and the segmentation clock. J Embryol Exp Morphol 131: 1221-1233.

COX PG (1969). Some aspects of tail regeneration in the lizard, Anolis carolinensis. I. A description based on histology and autoradiography. J Exp Zool 171: 127-149.

CRAWFORD NG, FAIRCLOTH BC, MCCORMACK JE, BRUMFIELD RT, WINKER K, and GLENN TC (2012). More than 1000 ultraconserved elements provide evidence that turtles are the sister group of archosaurs. Biol Lett 8: 783-786.

CRAWFORD NG, PARHAM JF, SELLAS AB, FAIRCLOTH BC, GLENN TC, PAPENFUSS TJ, HENDERSON JB, HANSEN MH, and SIMISON WB (2015). A phylogenomic analysis of turtles. Mol Phylogenet Evol 83: 250-257. (DOI:10.1016/j. ympev.2014.10.021).

DAVIDSON NM and OSHLACKA(2014). Corset: enabling differential gene expression analysis for de novo assembled transcriptomes. Genome Biol 15: 410.

DONOGHUE PCJ and BENTON MJ (2007). Rocks and clocks: calibrating the Tree of Life using fossils and molecules. Trends Ecol Evol 22: 424-431.

ECKALBAR WL, HUTCHINS ED, MARKOV GJ, ALLEN AN, CORNEVEAUX JJ, LINDBLAD-TOH K, DI PALMA F, ALFÖLDI J, HUENTELMAN MJ, and KUSUM K (2013). Genome reannotation of the lizard Anolis carolinensis based on 14 adult and embryonic deep transcriptomes. BMC Genomics 14: 49.

ECKALBAR WL, LASKU E, INFANTE CR, ELSEY RM, MARKOV GJ, ALLEN AN, CORNEVEAUX JJ, LOSOS JB, DENARDO DF, HUENTELMAN MJ, WILSON RAWLS J, RAWLS A, and KUSUMI K (2012). Somitogenesis in the anole lizard and alligator reveals evolutionary convergence and divergence in the amniote segmentation clock. Dev Biol 363: 308-319.

OZBUDAK EM and POURQUIÉ O. (2008). The vertebrate segmentation clock: the tip of the iceberg. Curr Opin Genet Dev 18: 317-323.

EZKURDIA I, JUAN D, RODRIGUEZ JM, FRANKISH A, DIEKHANS M, HARROW J, VAZQUEZ J, VALENCIA A, and TRESS ML (2014) Multiple evidence strands suggest that there may be as few as 19,000 human protein-coding genes. Hum Mol Genet 23: 5866-5878.

FARMER CG (1999). Evolution of the vertebrate cardio-pulmonary system. Annu Rev Physiol 61: 573-592.

FISHER RE, GEIGER LA, STROIK LK, HUTCHINS ED, GEORGE RM, DENARDO DF, KUSUMI K, RAWLS JA, and WILSON RAWLS J (2012). A Histological Comparison of the Original and Regenerated Tail in the Green Anole, Anolis carolinensis. Anat Rec 295: 1609-1619.

FUJITA MK, EDWARDS SV, and PONTING CP (2011). The Anolis lizard genome: an amniote genome without isochores. Genome Biol Evol 3: 974-984.

GANS C (1975). Tetrapod limblessness: evolution and functional corollaries. Amer Zool 15: 455-467.

GENOME 10K COMMUNITY OF SCIENTISTS (2009). Genome 10K: a proposal to obtain whole-genome sequence for 10,000 vertebrate species. J Hered 100: 659-674.

GIBBONS JG, JANSON EM, HITTINGER CT, JOHNSTON M, ABBOT P, and ROKAS $A$ (2009). Benchmarking next-generation transcriptome sequencing for functional and evolutionary genomics. Mol Biol Evol 26: 2731-2744.

GILBERT C, MEIK JM, DASHEVSKY D, CARD DC, CASTOE TA and SCHAACK S (2014). Endogenous hepadnaviruses, bornaviruses and circoviruses in snakes. Proc Biol Sci 281: 20141122

GILBERT RWD, VICKARYOUS MK, and VILORIA-PETIT AM (2013). Characterization of TGF $\beta$ signaling during tail regeneration in the leopard Gecko (Eublepharis macularius). Dev Dyn 242: 886-896.

GILBERT SF (2001). Morphogenesis of the turtle shell: the development of a novel structure in tetrapod evolution. In Evolution \& Development, pp. 47-58.

GOMEZC, ÖZBUDAKEM, WUNDERLICHJ, BAUMANND, LEWISJ, and POURQUIE $\mathrm{O}$ (2008). Control of segment number in vertebrate embryos. Nature 454:335-339.

GOMEZ C and POURQUIE O (2009). Developmental control of segment numbers in vertebrates Eds DG Blackburn and MK Richardson. J Exp Zool Part B: Mo Dev Evol 312B: 533-544

GOSSLER A and TAM P (2002). Somitogenesis: segmentation of the paraxial mesoderm and the delineation of tissue compartments. In Mouse Development (Eds J Rossant and P Tam). Mouse development, San Diego.

GRABHERR MG, HAAS BJ, YASSOUR M, LEVIN JZ, THOMPSON DA, AMIT I, ADICONIS X, FAN L, RAYCHOWDHURY R, ZENG Q et al. (2011). Full-length transcriptome assembly from RNA-Seq data without a reference genome. Nat Biotechnol 29: 644-652.

GREEN RE, BRAUN EL, ARMSTRONG J, EARL D, NGUYEN N, HICKEY G, VANDEWEGE MW, ST. JOHN JA, CAPELLA-GUTIERREZ, CASTOE TA et al. (2014). Three crocodilian genomes reveal ancestral patterns of evolution among archosaurs. Science 346: 1254449.

GREER AE (1991). Limb reduction in squamates: identification of the lineages and discussion of the trends. J Herpet 25: 166

GREER AE (1987). Limb reduction in the lizard genus Lerista. 1. variation in the number of phalanges and presacral vertebrae. J Herpet 21: 267.

GUTTMAN M, GARBER M, LEVIN JZ, DONAGHEY J, ROBINSON J, ADICONIS $X$, FAN L, KOZIOL MJ, GNIRKE A, NUSBAUM C, RINN JL, LANDER ES, and REGEV A (2010). Ab initio reconstruction of cell type-specific transcriptomes in mouse reveals the conserved multi-exonic structure of lincRNAs. Nat Biotechnol 28: 503-510.

HAASBJ, PAPANICOLAOU A, YASSOUR M, GRABHERR M, BLOOD PD, BOWDEN J, COUGER MB, ECCLES D, LI B, LIEBER M et al. (2013). De novo transcrip sequence reconstruction from RNA-seq using the Trinity platform for reference generation and analysis. Nat Protoc 8: 1494-1512.

HAN M, YANG X, LEE J, ALLAN CH, and MUNEOKA K (2008). Development and regeneration of the neonatal digit tip in mice. Dev Biol 315: 125-135.

HAN M, YANG X, TAYLOR G, BURDSAL CA, ANDERSON RA, and MUNEOKA K (2005). Limb regeneration in higher vertebrates: Developing a roadmap. Anat Rec 287B: 14-24.

HANDRIGAN GR and WASSERSUG RJ (2007). The anuran Bauplan: a review of the adaptive, developmental, and genetic underpinnings of frog and tadpole morphology. Biol Rev 82: 1-25.

HOLLEY SA (2007). The genetics and embryology of zebrafish metamerism Eds O Pourquié and JF Fallon. Dev Dyn 236: 1422-1449.

HORNETT EA and WHEAT CW (2012). Quantitative RNA-Seq analysis in non-mode species: assessing transcriptome assemblies as a scaffold and the utility of evolutionary divergent genomic reference species. BMC Genomics 13: 1.

HUGHES A and NEW D (1959). Tail regeneration in the geckonid lizard, Sphaerodactylus. J Embryol Exp Morphol 7: 281-302.

HUTCHINS ED, MARKOV GJ, ECKALBARWL, GEORGE RM, KING JM, TOKUYAMA MA, GEIGER LA, EMMERT N, AMMAR MJ, ALLEN AN et al. (2014). Transcriptomic analysis of tail regeneration in the lizard Anolis carolinensis reveals activation of conserved vertebrate developmental and repair mechanisms. PLoS ONE 9: e105004.

INTERNATIONAL CHICKEN GENOME SEQUENCING CONSORTIUM (2004) Sequence and comparative analysis of the chicken genome provide unique perspectives on vertebrate evolution. Nature 432: 695-716.

ITEN LE and BRYANT SV (1973). Forelimb regeneration from different levels of amputation in the newt, Notophthalmus viridescens: Length, rate, and stages. Dev Genes Evol 173: 263-282.

JANES DE, ORGAN CL, FUJITA MK, SHEDLOCK AM, and EDWARDS SV (2010). Genome evolution in Reptilia, the sister group of mammals. Annu Rev Genomics Hum Genet 11: 239-264.

KEYTE AL, SMITH KK (2014). Heterochrony and developmental timing mechanisms: Changing ontogenies in evolution. Semin Cell Dev Biol 34: 99-107.

KNAPP D, SCHULZ H, RASCON CA, VOLKMER M, SCHOLZ J, NACU E, LE M, NOVOZHILOV S, TAZAKI A, PROTZE S, JACOB T, HUBNER N, HABERMANN $B$, and TANAKAEM (2013). Comparative transcriptional profiling of the axolotl limb identifies a tripartite regeneration-specific gene program PLOS ONE 8: e61352.

KOSHIBA-TAKEUCHI K, MORI AD, KAYNAK BL, CEBRA-THOMAS J, SUKONNIK T, GEORGES RO, LATHAM S, BECK L, BECK L, HENKELMAN RM, BLACK BL, OLSON EN, WADE J, TAKEUCHI JK, NEMER M, GILBERT SF, and BRUNEAU BG (2009). Reptilian heart development and the molecular basis of cardiac chamber evolution. Nature 461: 95-98.

KROL AJ, ROELLIG D, DEQUÉANT M-L, TASSY O, GLYNN E, HATTEM G MUSHEGIAN A, OATES AC, and POURQUIÉ O (2011). Evolutionary plasticity of segmentation clock networks. J Embryol Exp Morphol 138: 2783-2792.

KURATANI S, KURAKU S, and NAGASHIMA H (2011). Evolutionary developmenta perspective for the origin of turtles: the folding theory for the shell based on the developmental nature of the carapacial ridge. Evol Dev 13: 1-14.

KUSUMI K, MAY CM, and ECKALBAR WL (2013). A large-scale view of the evolu- 
tion of amniote development: insights from somitogenesis in reptiles. Curr Opin Genetics Dev 23: 491-497.

LANDE R (1978). Evolutionary mechanisms of limb loss in tetrapods. Evolution 32: 73.

LANDERES, LINTON LM, BIRRENB, NUSBAUM C, ZODY MC, BALDWIN J, DEVON K, DEWAR K, DOYLE M, FITZHUGH W et al. (2001). Initial sequencing and analysis of the human genome. Nature 409: 860-921.

LI C, WU X-C, RIEPPEL O, WANG L-T, and ZHAO L-J (2008). An ancestral turtle from the Late Triassic of southwestern China. Nature 456: 497-501.

LINDBLAD-TOH K, WADE CM, MIKKELSEN TS, KARLSSON EK, JAFFE DB, KAMAL M, CLAMP M, CHANG JL, KULBOKAS EJ 3RD, ZODY MC et al. (2005). Genome sequence, comparative analysis and haplotype structure of the domestic dog. Nature 438: 803-819.

LIU Y, QIN X, SONG X-ZH, JIANG H, SHEN Y, DURBIN KJ, LIEN S, KENT MP, SODELAND M, REN Y, ZHANG L, SODERGREN E, HAVLAK P, WORLEY KC WEINSTOCK GM, and GIBBS RA (2009). Bos taurus genome assembly. BMC Genomics 10: 180.

LYSON TR, SPERLING EA, HEIMBERG AM, GAUTHIER JA, KING BL, and PETERSON KJ (2012). MicroRNAs support a turtle + lizard clade. Biol Lett 8: 104-107.

MCCLEAN K and VICKARYOUS MK (2011). A novel amniote model of epimorphic regeneration: the leopard gecko, Eublepharis macularius. BMC Dev Biol 11: 50.

MESCHER AL (1996). The cellular basis of limb regeneration in urodeles. Int J Dev Biol 40: 785-795

MIKKELSEN TS, WAKEFIELD MJ, AKEN B, AMEMIYA CT, CHANG JL, DUKE S, GARBER M, GENTLES AJ, GOODSTADT L, HEGER A et al. (2007). Genome of the marsupial Monodelphis domestica reveals innovation in non-coding sequences. Nature 447: 167-177.

MILLER HC, BIGGS PJ, VOELCKEL C, and NELSON NJ (2012). De novo sequence assembly and characterisation of a partial transcriptome for an evolutionarily distinct reptile, the tuatara (Sphenodon punctatus). BMC Genomics 13: 439

PARK W, KIM J, KIM HJ, CHOI J, PARK J-W, CHO H-W, KIM B-W, PARK MH, SHIN T-S, CHO S-K et al. (2014). Investigation of De Novo Unique Differentially Expressed Genes Related to Evolution in Exercise Response during Domestication in Thoroughbred Race Horses. PLOS ONE 9: e91418.

PEADON AM and SINGER M (1966). The blood vessels of the regenerating limb of the adult newt, Triturus. J Morphol 118: 79-89.

PYRON RA (2010). A likelihood method for assessing molecular divergence time estimates and the placement of fossil calibrations. Syst Biol 59: 185-194.

PYRON RA and BURBRINK FT (2014). Early origin of viviparity and multiple reversions to oviparity in squamate reptiles Ed. L Harmon. Ecology Letters 17: 13-21.

RAWLS A and FISHER RE (2010). Development and Functional Anatomy of the Spine. In The Genetics and Development of Scoliosis (Eds K Kusumi and SL Dunwoodie). Springer New York, New York, NY, pp. 21-46.

RICHARDSON MK, ALLEN SP, WRIGHT GM, RAYNAUD A, and HANKEN J (1998). Somite number and vertebrate evolution. J Embryol Exp Morphol 125: 151-160.

RITZMAN TB, STROIK LK, JULIK E, HUTCHINS ED, LASKU E, DENARDO DF, WILSON RAWLS J, RAWLS JA, KUSUMI K, and FISHER RE (2012). The Gross Anatomy of the Original and Regenerated Tail in the Green Anole (Anolis carolinensis). Anat Rec 295: 1596-1608.

ROBERTSON G, SCHEIN J, CHIU R, CORBETT R, FIELD M, JACKMAN SD, MUNGALL K, LEE S, OKADA HM, QIAN JQ et al. (2010). De novo assembly and analysis of RNA-seq data. Nat Methods 7: 909-912.

ROČKOVÁ H and ROČEK Z (2005). Development of the pelvis and posterior part of the vertebral column in the Anura. J Anat 206: 17-35.

SCHULZ MH, ZERBINO DR, VINGRON M, and BIRNEY E (2012). Oases: robust de novo RNA-seq assembly across the dynamic range of expression levels. Bioinformatics 28: 1086-1092.

SCHWARTZ TS, TAE H, YANG Y, MOCKAITIS K, VAN HEMERT JL, PROULX SR, $\mathrm{CHOIJ}-\mathrm{H}$, and BRONIKOWSKI AM (2010). Agarter snake transcriptome: pyrosequencing, de novo assembly, and sex-specific differences. BMC Genomics 11:694.

SHAFFER HB, MINX P, WARREN DE, SHEDLOCK AM, THOMSON RC, VALENZUELA N, ABRAMYAN J, AMEMIYA CT, BADENHORST D, BIGGAR KK et al. (2013). The western painted turtle genome, a model for the evolution of extreme physiological adaptations in a slowly evolving lineage. Genome Biol 14: R28.

SIMPSON SB (1965). Regeneration of the lizard tail. Regeneration in Animals and Related Problems: 431-443.
SINGER M (1974). Neurotrophic control of limb regeneration in the newt. Ann NY Acad Sci 308-322.

SMITH AR and WOLPERT L (1975). Nerves and angiogenesis in amphibian limb regeneration. Nature 257: 224-225.

SPARROW DB (2008). Old wares and new: five decades of investigation of somitogenesis in Xenopus laevis. In Somitogenesis (Eds M Maroto and NV Whittock). New York, pp. 73-94.

ST JOHN JA, BRAUN EL, ISBERG SR, MILES LG, CHONG AY, GONGORA J, DALZELL P, MORAN C, BED'HOM B, ABZHANOV A et al. (2012). Sequencing three crocodilian genomes to illuminate the evolution of archosaurs and amniotes. Genome Biol 13: 415.

STOCUM DL and CAMERON JA (2011). Looking proximally and distally: 100 years of limb regeneration and beyond Eds MA Ros and JF Fallon. Dev Dyn 240: 943-968.

TAKEO M, CHOU WC, SUN Q, LEE W, and RABBANI P (2013). Wnt activation in nail epithelium couples nail growth to digit regeneration. Nature 499: 228-232.

THE ENCODE PROJECT CONSORTIUM (2012). An integrated encyclopedia of DNA elements in the human genome. Nature 489: 57-74.

TRAPNELL C, ROBERTS A, GOFF L, PERTEA G, KIM D, KELLEY DR, PIMENTEL H, SALZBERG SL, RINN JL, and PACHTER L (2012). Differential gene and transcript expression analysis of RNA-seq experiments with TopHat and Cufflinks. Nat Protoc 7: 562-578.

TRUEB L and HANKEN J (1992). Skeletal development in Xenopus laevis (Anura: Pipidae). J Morphol 214: 1-41.

TZIKA AC, HELAERS R, SCHRAMM G, and MILINKOVITCH MC (2011). Reptiliantranscriptome v1.0, a glimpse in the brain transcriptome of five divergent Sauropsida lineages and the phylogenetic position of turtles. Evodevo 2: 19.

VIJAY N, POELSTRA JW, KÜNSTNER A, and WOLF JBW (2012). Challenges and strategies in transcriptome assembly and differential gene expression quantification. A comprehensive in silicoassessment of RNA-seq experiments. $\mathrm{Mol}$ Ecol 22: $620-634$

VONK FJ, CASEWELL NR, HENKEL CV, HEIMBERG AM, JANSEN HJ, MCCLEARY RJ, KERKKAMP HM, VOS RA, GUERREIRO I, CALVETE JJ et al. (2013). The king cobra genome reveals dynamic gene evolution and adaptation in the snake venom system. Proc Natl Acad Sci USA 110: 20651-20656.

WADE CM, GIULOTTO E, SIGURDSSON S, ZOLI M, GNERRE S, IMSLAND F, LEAR TL, ADELSON DL, BAILEY E, BELLONE RR et al. (2009). Genome sequence, comparative analysis, and population genetics of the domestic horse. Science 326: 865-867.

WAN QH, PAN SK, HU L, ZHU Y, XU PW, XIA JQ, CHEN H, HE GY, HE J, NI XW et al. (2013). Genome analysis and signature discovery for diving and sensory properties of the endangered Chinese alligator. Cell Res 23: 1091-1105.

WANG Z, PASCUAL-ANAYA J, ZADISSA A, LI W, NIIMURA Y, HUANG Z, LI C WHITE S, XIONG Z, FANG D et al. (2013). The draft genomes of soft-shell turtle and green sea turtle yield insights into the development and evolution of the turtle-specific body plan. Nat Genet 45: 701-706

WARREN WC, HILLIER LW, MARSHALL GRAVES JA, BIRNEY E, PONTING CP, GRÜTZNER F, BELOV K, MILLER W, CLARKE L, CHINWALLAAT et al. (2008). Genome analysis of the platypus reveals unique signatures of evolution. Nature 453: 175-183

WIENS JJ, BRANDLEY MC, and REEDERTW (2006). Why does a trait evolve multiple times within a clade? Repeated evolution of snakeline body form in squamate reptiles. Evolution 60: 123-141.

WU C-H, TSAI M-H, HO C-C, CHEN C-Y, and LEE H-S (2013). De novo transcriptome sequencing of axolotl blastema for identification of differentially expressed genes during limb regeneration. BMC Genomics 14: 434.

ZÁKÁNY J, KMITA M, ALARCON P, LA POMPA DE JL, and DUBOULE D (2001). Localized and transient transcription of of Hox gene suggest a link between patterning and the segmentation clock. Cell 106: 207-217.

ZHANG G, COWLED C, SHI Z, HUANG Z, BISHOP-LILLY KA, FANG X, WYNNE JW XIONGZ, BAKERML, ZHAOW etal. (2013). Comparative analysis of bat genomes provides insight into the evolution of flight and immunity. Science 339: 456-460.

ZHANG G, LI C, LI Q, LI B, LARKIN DM, LEE C, STORZ JFM, ANTUNES A, GREENWOLD MJ, MEREDITH RW et al. (2014). Comparative genomics reveals insights into avian genome evolution and adaptation. Science 346: 1311-1320. 


\section{Further Related Reading, published previously in the Int. J. Dev. Biol.}

Sexual dimorphism of AMH, DMRT1 and RSPO1 localization in the developing gonads of six anuran species

Rafal P. Piprek, Anna Pecio, Katarzyna Laskowska-Kaszub,Jacek Z. Kubiak and Jacek M. Szymura

Int. J. Dev. Biol. (2013) 57: 891-895

Dual embryonic origin of the hyobranchial apparatus in the Mexican axolotl (Ambystoma mexicanum)

Asya Davidian and Yegor Malashichev

Int. J. Dev. Biol. (2013) 57: 821-828

Clonal analyses in the anterior pre-placodal region: implications for the early lineage bias of placodal progenitors

Sujata Bhattacharyya and Marianne E. Bronner

Int. J. Dev. Biol. (2013) 57: 753-757

Amphibian interorder nuclear transfer embryos reveal conserved embryonic gene transcription, but deficient DNA replication or chromosome segregation

Patrick Narbonne and John B. Gurdon

Int. J. Dev. Biol. (2012) 56: 975-986

Origins of $\mathrm{Cdx} 1$ regulatory elements suggest roles in vertebrate evolution

Stephen J. Gaunt and Yu-Lee Paul

Int. J. Dev. Biol. (2011) 55: 93-98

Reptile scale paradigm: Evo-Devo, pattern formation and regeneration

Cheng Chang, Ping Wu, Ruth E. Baker, Philip K. Maini, Lorenzo Alibardi and Cheng-Ming Chuong

Int. J. Dev. Biol. (2009) 53: 813-826

Proteomics analysis of regenerating amphibian limbs: changes during the onset of regeneration

Michael W. King, Anton W. Neff and Anthony L. Mescher

Int. J. Dev. Biol. (2009) 53: 955-969

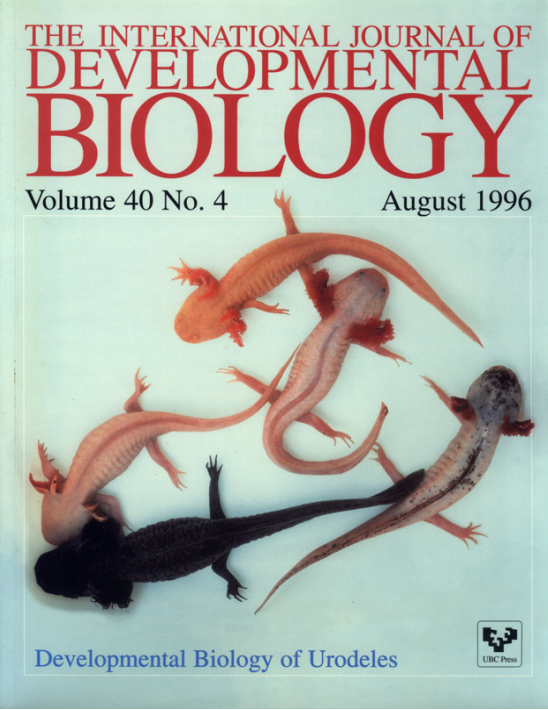

5 yr ISI Impact Factor $(2013)=2.879$
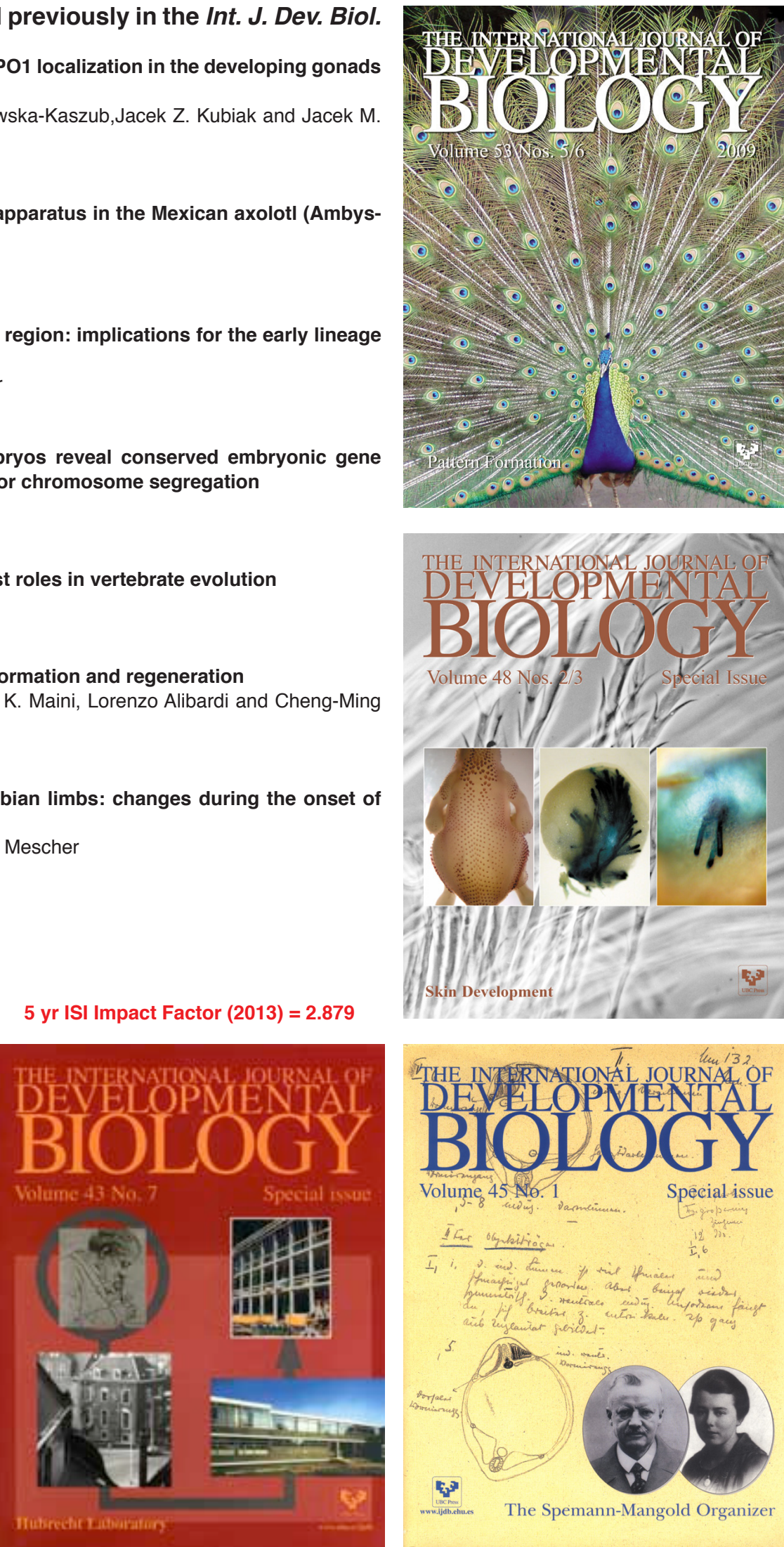

Volume 45 No. 1

Special issue

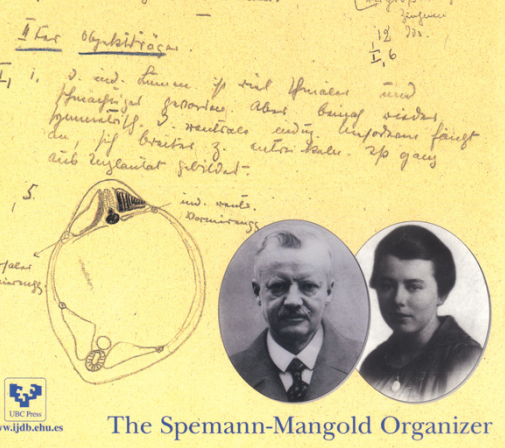

